induration at the lower part of the tumor, and the fluctuation obscurely felt through the thickened tunica vaginalis; you saw during the operation the change in the structure of the tunica vaginalis, and that the inturation of the epididymis, or rather in the tunica albuginea contiguous, though considerable, was not such as to render castration necessary. This is just the description of case in which the operation by incision is to be preferred to any other, the hydrocele being evidently complicated with morbid changes in the testis or its investing membranes, the precise extent of which changes can only be ascertuined after the tumor is laid open. There is occasionally much difficulty in the diagnosis of hydrocele, and surgeons of the greatest eminence and skill have been at times deceived; this fact should be a lesson to us on the importance of making the most careful examination, regardless of its tediousness, which it is the interest of the patient to endure till the surgeon's mind is satisfied. While the hydrocele is cured by a change in the action of the vessels of the tunica vaginalis from the effects of the incision, the absorbents become excited during the subsequent suppurative process, and generally carry off those indurations which do not amount in their character to more than that condition termed sclerocele.

In the amputation just performed there was a curious feature displayed, and one of great interest to the operating surgeon, I mean the change in the proportionate calibre of the arteries, and the violence of the hæmorrhage during the operation. I always, you know, amputate without any tourniquet, and have not yet seen reason to repent this mode, effectual pressure being made on the main artery by a good assistant. The change in the calibre of the arteries arises from the long continued previous disease in the extremity beyond the main trunk, diminishing when the limb is not used, while the lateral branches become enormously enlarged by the inflammatory action they sustain. The obstinacy of the hæmorrhage from the vessels was from the induration in the structures through which they pass, preventing retraction as effectually as if each artery ran through a canal of bone. The coats of such arteries are not always healthy; and in one such case, which occurred in my private practice ten years ago, a large arterial jet suddenly burst forth ten days after amputation, and through a stump which was all but healed. I might have dissected long in the stump to find the end of the bleeding vessel, which was evidently the femoral artery, and then I should have caught it at its diseased part ; this consideration induced me to take another course. I cut down upon and tied the artery in the groin, which was done before the at'endants had time to make up the patient's bed; the hemorrhage of course ceased at once, and, to use a common expression, the patient never looked behind him afterwards, recovering with the greatest rapidity."

\section{ISCHURIA RENALIS.}

TO THE EDITORS OF THE PROVINCIAL MEDICAL AND SURGICAL JOURNAL.

Gentreyen, - The following case of Ischuria may perhaps possess interest enough to justify its insertion in your periodical. I attended the patient with Mr. Atkinson, of Wylain, to whom I am indebted for the following report, which I give verbatim.

"John Johnson, æt. 41, miller, has been for some time complaining of lassitude and uneasiness in the lumbar region, for which he has taken aperient medicines, without relief.

"This day (Sept. 15th, 1839), at 6 P.x. I was called in for the first time to visit him. On inquiry I find that he attended Newcastle market, and the day being very wet, $w$ as exposed to rain, and felt much worse during the night, passing a very sinall quantity of urine. He slept little and talked much during the short periods of repose. The symptoms under which I found him labouring were,-Pain in the lumbar region; tenderness in the hypogastrium; tongue covered with a whitish fur, brown in centre, and moist; pulse 84, rather full; temperature of skin, natural; no desire to pass urine, and on each attempt only a fluid drachm, or thereabouts, was voided; bowels rather constipated. To be bled to 14 ounces; to have six grains of calomel at once, and a purgative draught four hours afterwards. Spirit of nitrous æther, four drachms ; tincture of squills, two drachms; gum mixture, one ounce; water, six ounces; two spoonsful every second hour. After the abstraction of blood he felt much relieved.

"Sept. 16th, 9 A.M. Patient has passed a restless night, but is much relieved. The bowels have been freely opened; the urine, however, still discharged in similar quantities. Continue the medicines.

"Vespere. Much the same; pulse 60; has now some thirst; the quantity of urine voided in the last 24 hours amounts to not more than three fluid ounces. I now introdued the catheter, but found no accumulation in the bladder. Prescribed a warm bath.

" 17 th. No improrement. More pain in the loins and also in the abdomen, but now more towards the umbilicus; has much nausea; the bowels have not been opened since the operation of the cathartic; the warm bath gare temporary relief; pulse 56 . Sulphate of magnesia, half an ounce; nitrate of potash, two scruples; tincture of cantharides, one drachm; spirit of nitrous æther, four drachms; water, seven ounces. Two spoonsful every third hour. A large blister over the loins.

"Vespere. Blister has acted well ; pain relieved in some degree; pulse 60 ; bowels not eracuated this day; has had some vomiting. To have six grains of calomel at once, and a purgative draught three hours afterwards. At bedtime he took the following draught: Spirit of nitrous æther, one drachm; sedative solution of opium, eight drops; camphor mixture, one ounce and a half.

"18th. Continues without any improvement. Seen at 9 A.м. by Dr. Fife, who prescribed the following:-Acetate of potass, three drachms; spirit of nitrous æther, four drachms ; pennyroyal water, eleven ounces. Two spoonsful every third hour. Calomel, powdered squills, and extract of conium, of each one grain. $A$ pill to be taken every fourth hour. In the evening he complained of pain in the abdomen, chiefly in the umbilical region, for which six leeches were applied, with relief; slept a little during the night; about four ounces of urine passed in the last 24 hoürs.

" 19th. Has some uneasiness in the head; answers questions drowsily; pulse 54 ; the abdominal pain relieved. Twelve leeches were applied to the mastoid processes, and a blister to the nape of the neck. Calomel, powdered squill, and digitalis, of each one grain ; to be taken every hour. Continue the mixture.

" 20th. 'The head quite reliered; in other respects the same; pulse variable, 54 in the recumbent posture; bowels have not been evacuated since the 18th. Blue pill, four grains ; powdered squill, one grain ; a pill to be taken every fourth hour. Acetate of potass, six drachms; spirit of juniper, seven drachms; tincture of squills, seven drachms; pennyroyal water, eleven drachms; two spoonsful every four hours. Muriate of morphia, one-third of a grain; camphor mixture, eleven drachms; spirit of nitrous æther, one drachm ; to be taken at night. Half an ounce of castor oil, at once.

" 21 st. After passing a restless night, he has become worse in every respect. Pulse varies from 48 to 34 ; complains of much pain in the loins and testicles, which however are not retracted, but, on the contrary, more than usually pendulous; severe pain, extending from the umbilical to both hypochondriac regions; thirst, some vomiting, with frequent retching. A warm bath at once; twelve leeches to the abdomen; the catheter to be pasied thrice a day. Oil of turpentine, four drachms; tincture of hyosciamus, four drachms; gum mixture, one ounce; water, four ounces. Three spoonsful every four hours. 
" During the day his sufferings increased; the only relief being that afforded by the warm bath, out of which he would scarcely remain for 15 minutes. The pulse varied from 48 to 54 during the day. In the evening hiccup came on, and distressed him much ; frequent vomiting. To have fortyfive drops of the solution of muriate of morphia; to be repeated, if necessary, in two hours.

" $22 \mathrm{~d}$. This morning ( $7 \frac{1}{2}$ A.M.) I found him easier; has slept at intervals during the night, but only about fifteen minutes at a time; has passed no urine since the introduction of the catheter, at midnight ; pulse 60 ; hiccup present, more or less, since 4 o'clock; thirst urgent. I introduced the catheter, and removed about five ounces of urine, possessing distinctly the odour of turpentine. At $100^{\prime}$ 'clock he was seen by Dr. Fife, who directed the continuance of the medicines prescribed yesterday. At this time he was free from pain; perfectly collected, and even cheerful, expressing himself much better. About half an hour afterwards he was attacked by a convulsion; after which he sank into a state of collapse ; presented a paralytic appearance of the face, and died at a quarter past twelve o'clock."

For the above very accurate report (considering that it was, in great measure, drawn up from scanty memoranda) I am obliged to Mr. Atkinson, whose attention to our unfortunate patient could not be surpassed, either in humanity or vigilance, and whose diagnosis, from the beginning. reflected the highest credit upon his judgment.

The feelings of a numerous and respectable connexion, I am sorry to say, prevented us having a post-mortem examination. This is the more to be regretted, from our comparatively limited knowledge of the pathology of this disease, notwithstanding the highly valuable contributions to this department of pathology by Drs. Bright and Christison.

The question may arise, whether this case was essentially Ischuria, or whether the suppression of urine arose as a mere consequence of inflammation of the kidney. To the former opinion I am certainly inclined, and for the following reasons, although I have little doubt of the presence of some degree of inflammatory action in the progress of the case: The symptoms described do not accord with those of acute nephritis, the pain being, in the first instance, by no meaus intense; the pulse very little excited, certainly not hard; little or no pyrexia present ; and the early suppression of urine, together with the pendulous state of the testes. The pulse, after the first few hours, was, in fact, preternaturally slow; on an average below 50 . The presence of somnolency was also, early in the case, a prominent and alarming symptom. The temperature of the skin was, for the most part, below the natural standard, and the slight degree of perspiration which occasionally existed, was distinctly and powerfully marked by the urinous odour. If further evidence were required, I would especially regard the progress and termination of this melancholy case; which, in my humble opinion, place the nature of the disease beyond all doubt. So marked was the tendency to cerebral affection, and so just the apprehension which it excited, that the fatal conclusion was only postponed by the instant application of the remedial agents above mentioned.

\section{I am, gentlemen,
Your obedient servant,} Geurge Fife, M.D.

\section{Newcastle-upon-Tyne, Dec. 10, 1840.}

P.S.-One remark I had nearly omitted, viz. That when I saw Mr. Johnson on the morning of his decease, such was the improvement that my hopes of his recovery were great ; and my prognosis to his family was only qualified by an apprehension, not only entertained but expressed, that the bead might still be affected. The hint which is now given, may not be thrown away on the junior readers of your Journal.

G. $\mathbf{F}$.

\section{PROVINCIAL MEDICAL AND SURGICAL ASSOCIATION.}

(Continued from p. 199.)

\section{REPORT OF THE POOR-LAW COMMITTEE, 1840.}

(Published by order of the Council.)

\$16. Your committee are able, from a personal knowledge of the facts, to give also a full report of the early medical arrangements, and consequent events in the three following unions :-

The Bridgewater Union was formed by Mr. Assistantcommissioner Weale, in 1836 . It contains a population of 28,566 , and 40 parishes, in which the medical salaries, before the formation of the union, amounted to $481 l$. exclusive of casualties and suspended orders, which were calculated by the board at 20 per cent., making a total (according to this estimate) of $577 l$., the average amount previously paid to 16 or 17 practitioners.

The guardians at once determined to reduce the amount to $363 l$. The medical men, aware that they had always been paid at too low a rate, remonstrated against such an extraordinary and unreasonable reduction, but ultimately acquiesced, on being assured by the chairman that the first year was one of probation, and that if the remuneration proved inadequate, it should be increased. The union was divided into seven districts, and surgeons, fully qualified, were appointed.

The conciliatory conduct of the medical men only delayed the crisis which a defence of professional character and interests rendered inevitable. At the expiration of the first year, the districts having been found inconveniently large, the board proposed to increase their number to eight, and to make the workhouse a distinct appointment, fixing the amount of district salaries at $370 l$., and the new workhouse (just then opened) at $30 l$. A notice to this effect was accordingly circulated.

The medical officers, however, "finding, from the experience of the past year, that they could not, with justice to the poor, the guardians, and themselves, continue their charge at the salaries proposed," and that the board was unmindful of the pledge given at first by the chairman, addressed the guardians to that effect; at the same tinie expressing their readiness to resume their duties on equitable terms. In this just remonstrance, the other principal practitioners in the union coincided.

Having been invited by the board to state their offers, the medical officers proposed salaries, varying from $3 d$. to $4 d$. a head on the population of the several districts, and $50 l$. for the workhouse, intended to contain 300 persons (that is about $4 \frac{1}{2} d$. a head on the population of the whole union). The total demand, therefore, was 528l. 16s. 4d.; viz. $50 l$. less than the former medical expenses.

The board summarily rejected this very moderate offer, $t$ and appointed to a portion of the union, two medical men of inferior qualification; the remaining portion being advertised in the London and provincial papers.

To facilitate their project, the guardians had redivided the union into only six districts, in direct opposition to their slightly improved propositions of the previous month. They also raised their offer from $400 l$. to $435 l$., in order to attract adventurers.

One of the three candidates, obtained by advertisement, was appointed to an extensive district. He was unknown to the board, unacquainted with the locality, not a member of the College of Surgeons; his previous history was far from creditable, and he obtained the situation by assuming fictitious titles and qualifications. Three of the resident practitioners, who were more disposed than their brethren to accept the terms last offered, were appointed to the

- A reference to the parish kooks will show that these extra expense amounted to nearly $200 \mathrm{l}$. or 40 per cent.

$\uparrow$ Vide Dr. Kay's evidence (5073); and Col. Court's estimate for Wilts, 4t $\frac{1}{2}$. $a$ head, and for Hants, $5 \frac{1}{2} d$.

$\ddagger$ Mr. John Rodney Ward. See Lancet, Aug. 18, 1838.
. 